\title{
ВІРОГІДНІСТЬ ВИНИКНЕННЯ ТА УМОВИ РОЗВИТКУ ТРІЩИНИ В НАПОВНЕНИХ ПОЛІМЕРАХ ОБМЕЖЕНОЇ ТОВЩИНИ
}

\author{
๑ А. С. Морозов, к.т.н., доцент, НТУУ «КПІ», Київ, Україна
Исследуются условия развития трещины в наполненных полимерных пленках.

\section{Conditions of growth crack at replete polymer films is determined.}

\section{Постановка проблеми}

Поліграфічне покриття у більшості випадків є фарбовою плівкою на основі наповнених полімерів, структура яких була обумовлена поступовим перетворенням рідкоподібного в'яжучого у тверду композиційну сполуку. Кінетика цього перетворення визначається гамою фізико-хімічних показників:

- швидкістю всотування і випаровування розчинника;

- градієнтом його концентрації у локальних поверхневих зонах задруковуваних матеріалів;

- присутністю сторонніх включень у вигляді мікрокрапель води та інших домішок.

Оптимізація процесу полімеризації рідкої субстанції, якою $€$ поліграфічна фарба, необхідна для підвищення якості поліграфічної продукції, зокрема, міцністних властивостей, обумовлених вірогідністю виникнення тріщин. Для розв'язання таких питань треба звернути увагу на дію вступу системних факторів, сприяючих утворенню початкової стадії руйнування структури пігментованого полімеру, а також проаналізувати ї причинно-наступні зв'язки.

\section{Мета роботи}

Метою даного дослідження $€$ аналіз можливого процесу виникнення тріщини та кінетики ії росту у наповнених полімерних плівках поліграфічного призначення.

\section{Результати проведених досліджень}

Пігментація плівкоутворювальних систем сповільнюе випаровування розчинників, особливо якщо використовуються пігменти і наповнювачі лускатої будови (алюмінієва або бронзова пудра, мікрослюда та ін.). Ці фактори, пов'язані між собою. Так, наприклад, при зникненні розчинників внаслідок неоднакової їх концентрації в поверхневому $\mathrm{C}_{2}$ і глибинному $\mathrm{C}_{1}$ шарах створюється градієнт поверхневого натягу по товщині плівки: $\Delta \sigma=\sigma_{2}-\sigma_{1}$. Його значення тим більше, чим більше різниця $\mathrm{C}_{1}-\mathrm{C}_{2}$ і чим сильніше розрізняються поверхневі натяги плівкоутворювача і розчинника.

Наявність градієнта $\Delta \sigma$ викликає утворення турбулентних потоків у розчині, які і створюють відповідний рельєф його поверхні. При досягненні високої в'язкості лакофарбового матеріалу в поверхневому шарі цей рельєф фіксується в плівці у 
вигляді відповідного малюнка, утворення якого небажано, тому що знижуються блиск і погіршується зовнішній вигляд покриття.

Якщо градієнт концентрації можна віднести до зовнішнього чинника, який формує структурну неоднорідність фарбової плівки, то металеві частинки є внутрішнім структуроутворювачем, який генерує локальні зони внутрішніх напружень [1].

При невеликому вмісті (10 \%) наповнювача (металевих пігментів) в полімерній плівці навколо його частинок виявляється більш орієнтовна і напружена структура, а забарвлення структури полімеру навколо зерен наповнювача нерівномірне і воно змінюється по перерізу від поверхні наповнювача до зовнішніх шарів плівки. Встановлено [2], що змінення кольору полімерної складової пов'язано 3 нерівномірним розподілом внутрішніх напружень. При цьому максимальні напруження проявляють себе в шарах, прилягаючих до поверхні наповнювача. При дії таких напружень в полімерній основі з'являються мікротріщини, які у деякій мірі послаблюють її зв'язок з металевими пігментами.

Імовірність перетворення мікротріщини у тріщину руйнування в зоні частинки обумовлена реакційним впливом агресивного середовища при експлуатації металізованого поліграфічного покриття (особливо на бігбордах рекламного спрямування) в умовах міської інфраструктури. Реакційний вплив може полягати в підвищенні локального тиску, темпе- ратурних аномаліях, постійного змінення вологи, дії сонячного світла і в свою чергу впливати на екстрагованість базових компонентів із металізованої плівки.

При руйнуванні локального об'єму плівки частина пружньої енергії $\mathrm{E}_{0}$, що підводиться в зону руйнування, витрачається на роботу пластичної деформації $\mathrm{E}_{\text {пл }}$ та утворення поверхонь розриву $E_{n}$, а інша частина перетворюється в кінетичну енергію $\mathrm{E}_{\mathrm{K}}$ розвитку тріщини, тобто маємо [3]:

$$
E=E_{\Pi} ת+E_{\Pi}+E_{k} .
$$

У відповідності 3 ергодинамічною теорією тіло вважається зруйнованим, якщо хоча б в одному макрооб'ємі, відповідальному за руйнування, щільність внутрішньої енергії досягає критичної величини $u^{*}$. Цьому моменту відповідає поява у системі біфуркацій утворення тріщини критичного розміру та різка локалізація процесу в її основі. Умова локального руйнування записується у вигляді:

$$
\begin{aligned}
& u\left(r^{\star}, t^{\star}\right)=u\left(r^{\star}, 0\right)+ \\
& +\int_{0}^{t^{*}} u\left(r^{\star}, t\right) d t=\text { const },
\end{aligned}
$$

де $u\left(r^{\star}, 0\right)$ - щільність внутрішньої енергії матеріалу у вихідному (до деформування $\mathrm{t}=0)$ стані, $\mathrm{u}\left(\mathrm{r}^{\star}, \mathrm{t}\right)$ - швидкість змінення щільності внутрішньої енергії в локальному макрооб'ємі матеріалу, відповідальному за руйнування, $r^{*}-$ параметр, що характеризує координати $\left(\mathrm{x}^{*}, \mathrm{y}^{*}, \mathrm{z}^{*}\right)$ локального об'єму тіла, відповідального за руйнування. 
Для рішення питання при критичне значення щільності $u_{*}$, яка накопичується у деформовуваних об'ємах до моменту їх руйнування (втрата стійкості кристалічної ґратки), скористуємося ідеєю про енергетичну аналогію процесів плавлення i механічного руйнування матеріалів [4].

Тому питому енергію $u_{*}$, накопичену в об'ємі матеріалу, відповідальному за руйнування, треба розглядувати як складову з двох частин: питомої енергії u"*, що витрачається на створення граничних статичних спотворень, зв'язаних з дислокаціями та іншими дефектами, зародкоутворюваними та затримуваними у матеріалі в процесі пластичної деформації, i питомої енергії $u^{» » *}$, що витрачається на руйнування міжатомних зв'язків в об'ємі з граничними статичними спотвореннями, тобто

$$
u_{*}=u^{\prime \prime} \star+u^{\prime \prime \prime} * .
$$

Далі приймається, що при деформуванні матеріалу увесь його об'єм V стане рівномірно поглинати енергію спотворень і до певного моменту буде насичений граничною енергією спотворень, рівною ентальпії матеріалу у твердому стані при температурі плавлення

$$
\mathrm{u}^{\prime \prime}{ }_{*}=\Delta \mathrm{H}_{\mathrm{TB}}=\int_{0}^{\mathrm{T}} \mathrm{cdT},
$$

де $\Delta \mathrm{H}_{\text {тв }}$ - ентальпія матеріалу у твердому стані; $\mathrm{c}_{\mathrm{p}}$ - теплоємність матеріалу.

У той же час критичний об'єм руйнування $\mathrm{V}_{\mathrm{p}}$ буде у цьому випадку по своїй величині менше вихідного V. Для порушення міжатомних зв'язків з граничними спотвореннями потрібно підвести додаткову енергію, рівну

$$
\mathrm{u}^{\prime \prime \prime} *=\left(\mathrm{V}_{\mathrm{p}} / \mathrm{V}\right) \mathrm{L}_{\mathrm{s}},
$$

де $L_{s}$ - прихована теплота плавлення.

Таким чином, сумарна питома внутрішня енергія, поглинена деформуємим об'ємом в процесі пластичної деформації, до моменту руйнування буде дорівнювати

$$
u_{*}=\int_{0}^{T} c d T+V_{p} / L_{s} .
$$

В залежності від структури матеріалу та умов деформування і руйнування співвідношення $\mathrm{V}_{\mathrm{p}} / \mathrm{V}$ може змінюватись в межах

$$
0<\mathrm{v}_{\mathrm{p}} \mathrm{N}<1,0,
$$

тому критичне значення внутрішньої енергії, поглинене деформуємим об'ємом, може змінюватись у межах

$$
\Delta \mathrm{H}_{\mathrm{TB}}<\mathrm{u}_{*}<\Delta \mathrm{H}_{\mathrm{s}},
$$

де $\Delta \mathrm{H}_{\mathrm{s}}-$ ентальпія плавлення.

у локальному об'ємі, відповідальному за руйнування $\mathrm{V}_{\mathrm{p}} / \mathrm{V} \rightarrow 1$, тому

$$
\mathrm{u} * \rightarrow \Delta \mathrm{Hs} \text {. }
$$

При пластичному деформуванні великих об'ємів V в умовах однорідного напруженого стану до моменту утворення тріщин критичного розміру співвідношення $\mathrm{V}_{\mathrm{p}} / \mathrm{V} \rightarrow 0$, тому $\mathrm{u}_{*} \rightarrow \Delta \mathrm{H}_{\mathrm{TB}}$.

Навпаки, при тонкому диспергуванні матеріалу (в умовах зносу) $\mathrm{V}_{\mathrm{p}} \rightarrow \mathrm{V}$, тому $\mathrm{V}_{\mathrm{p}} / \mathrm{V} \rightarrow 1$ та $\mathrm{u} * \rightarrow \Delta \mathrm{H}_{\mathrm{s}}$. Такий процес спостерігається, зазвичай, при експлуатації металізованих поліграфічних покриттів. 
Прогнозувати структуру металонаповненого полімера можна ще на стадії вихідної поліграфічної фарби шляхом додавання необхідних компонентів, регулюючих в'язкість та пігментоутворення композиції, яка полімерізується.

В праці [5] була відмічена аналогія між текучістю в'язкої рідини, описувана співвідношенням

$$
\mathrm{d} \epsilon / \mathrm{dt}=1 / \eta \cdot \sigma,
$$

та пластичною текучістю твердого тіла, підпорядкованою співвідношенню

$$
\begin{gathered}
\mathrm{d} \epsilon / \mathrm{dt}=\mathrm{C}_{1} \mathrm{U}_{*} \cdot\left(\sigma-\sigma_{\mathrm{k}}\right)+ \\
+\mathrm{C}_{2} \mathrm{U} \cdot \mathrm{d} \sigma / \mathrm{dt}+1 / \mathrm{G} \cdot \mathrm{d} \sigma / \mathrm{dt} . \quad(10)
\end{gathered}
$$

Тут $€$ - деформація зсуву, $\mathrm{t}-$ час, $\sigma$ - напруга зсуву, $\mathrm{U}$ - концентрація активних дислокацій, $\sigma_{\mathrm{k}}-$ поверхня межі пружності, залежної від температури і деформації.

При переході через поверхню при $\sigma<\sigma_{\mathrm{k}}$ тепловий ефект відсутній, тобто при $\sigma>\sigma_{\mathrm{k}}$ $\mathrm{U}^{\star}>0$, а при $\sigma<\sigma_{\mathrm{k}} \mathrm{U}_{*} \approx 0$. При $\sigma>\sigma_{\mathrm{k}}$ співвідношення (9) перетворюється в (10).

Відмічено [6], що пластична деформація кристалічної частини наповнених полімерів нагадує вихрові переміщення турболізованої рідини при великих числах Рейнольдса. При цьому виділяються три типу вихру: перший мікровихор у вигляді часткової дислокації, другий статичний вихор, локалізований у конкретному місті кристалічної структури, у вигляді обертального фрагменту або стикової дислокації і третій - великомасштабні ротаційні нестійкості.
Аналогічні вихри можна виділити і в потоках в'язкої рідини, але вихри, виникаючі при пластичній деформації матеріалів, утворюються у середовищах з пам'ятю [7], тобто по векторам разорієнтування можна відновити картину вихороподібної пластичної текучості. Якщо притримуватися аналогії між пластичною деформацією і текучістю в'язкої рідини та можливістю описання цього процесу $з$ використанням критерія, подібного критерію Рейнольдса, то треба спочатку виділити ламінарне і турбулентне пластичні течії.

Точка переходу від ламінарної течії (одинарне ковзання) до турбулентної (множинне ковзання) є точкою біфуркації, а параметри, контролюючі цей перехід при рості тріщини, дають фундаментальну інформацію.

Таким чином, утягування у процес деформування дефектів різного рівня - точкових (міжвузілля, вакансії та їх комплекси), лінійних (дислокації різних типів), планарних (дефекти упаковки, малокутові границі) та, нарешті, об'ємних (макротріщини, мікропори) знаходить своє відображення у зміненні макроскопічних властивостей матеріалу. Послідовність виникнення структур, утворених дефектами різного рівня, залежить від попередньої історії досліджуваного матеріалу (рідка поліграфічна фарба), від виду початкової дисипативної структури, типу кристалічної ґратки, способу експлуатації, а також від вихідних компонентів. 
Сучасні теорії пояснюють рост утомної тріщини на основі діаграм циклічної тріщиностійкості. На рис. [7] розглянуто порогові ситуації з точки зору досягнення порогових значень амплітуди коефіцієнту інтенсивності напружень $\Delta \mathrm{K}$.

Першим порогом $€$, безумовно, амплітуда коефіцієнту інтенсивності напружень $\Delta \mathrm{K}_{\mathrm{th}}$, нижче якої тріщина, як гадають, практично не розвивається, хоча відомо, що при дуже низьких $\Delta \mathrm{K}$ ріст тріщини відбувається, але швидкість дуже мала. У зв'язку з асимптотичним характером кривої залежності швидкості росту утомної тріщини від $\Delta К$ у припороговій області діаграми циклічної тріщиностійкості (ДЦТ) якісне значення $\Delta \mathrm{K}_{\text {th }}$ залежить від вибраної базової швидкості розвитку тріщини.

Вважають також, що умовою для визначення даного порогу може бути певне вибране довільно число циклів, на протязі яких тріщина не просувається на якусь мінімальну відстань, яку можна виміряти. Умовність визначення $\Delta \mathrm{K}_{\text {th }}$ полягає також у залежності цього параметру від схеми змінення навантаження (підвищення або зниження) та ступеню його послідовного східчастого змінення. Тому видається доцільним та більш фізично обґрунтованим визначати величину $\Delta \mathrm{K}_{\text {th }}$ при детермінованій швидкості росту тріщини, а також визначати поріг при швидкості росту тріщини. Абсолютне значення якої дорівнює кванту руйнування $\mathrm{a}_{\mathrm{q}}$.

Ріст утомленої тріщини пов'язують $з$ кооперацією двох конкуруючих механізмів руйнування - мікрозсуву та мікровідриву, причому кожний акт просування тріщини пов'язано 3 утворенням критичного зародишу тріщини по механізму мікрозсуву та мікровідриву у залежності від структурного рівня деформації і характеру структурно-неврівноважених станів. Зародження мікротріщини по механізму мікрозсуву пов'язано з досягненням критичної щільності дислокацій (у площині ковзання), а по механізму відриву - 3 досягненням критичної щільності дисклінацій в елементі об'єму, який зазнав деформацію.

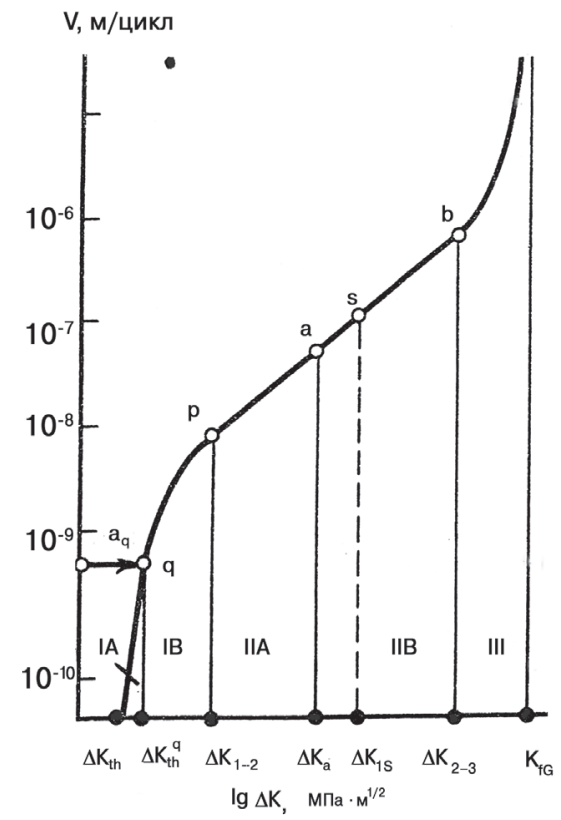

Кінетична діаграма циклічної тріщиностійкості

\section{Висновки}

Тверде тіло, яким є полімерна фарбова плівка, наповнена металевими пігментами, представляє собою елемент кон- 
струкції, і в процесі експлуатації випробує складний комплекс змінюваних по рівню, періодичності і тривалості циклічних навантажень. Багатофакторна ситуація із впливом на матеріал при розповсюдженні у ньому утомленої тріщини припускає комплексний аналіз процесів 3 позицій синергетики. Використання принципу аналогії дозволяє змоделювати механізми утворення утомної тріщини для класу матеріалів, маючих загалом кристалічну структуру, та в незначній мірі аморфну.

1. Морозов А. С. Внутрішні напруження та їх вплив на міцність і структуру фарбової металізованої плівки поліграфічного призначення / А. С. Морозов // Технологія і техніка друкарства. - 2010. - № 1. - С. 179-184. 2. Пахаренко В. А. Переработка полимерных композиционных материалов / В. А. Пахаренко, Р. А. Яковлева, А. В. Пахаренко. - К. : Воля, 2006. - 550 с. 3. Реморов В. Е. Оценка сопротивляемости разрушению трубных сталей по работе развития трещины / В. Е. Реморов, Н. А. Челышев, Ю. И. Пашков, А. Б. Каплан // Известия высших учебных заведений. Черная металлургия. - 1991. - № 8. - С. 31-34. 4. Панасюк В. В. Методы оценки трещиностойкости конструкционных материалов / В. В. Панасюк, А. Е. Андрейкив, С. Е. Ковчик. - К. : Наук. думка, 2001. - 277 с. 5. Шанявский А. А. Самоорганизация кинетики усталостных трещин / А. А. Шинявский // Синергетика и усталостное разрушение материалов. - М. : Наука, 1989. - 246 с. 6. Bernal I. D. Geometrical approach to the structure of liquids / J. Appl. Phys. Lett. - 2000. - Vol. 44. - № 9. - P. 874-876. 7. Шанявский А. А. Синергетический подход к построению единой диаграммы роста усталостных трещин в материалах / А. А. Шанявский, Е. М. Григорьев // Синергетика и усталостное разрушение материалов. - М. : Наука, 1989. - 246 с.

1. Morozov A. S. Vnutrishni napruzhennja ta jih vpliv na mitsnist' i strukturu farbovoj metalizovanoj plivki poligrafichnoho priznachennja / A. S. Morozov // Technolohija i tehnika drukarstva. - 2010. - \# 1. - S. 179-184. 2. Paharenko V. A. Pererabotka polimernih kompozitsionnih materialov / V. A. Paharenko, R. A. Jakovleva, A. V. Paharenko. - K. : Volja, 2006. - 550 s. 3. Remorov V. E. Otsenka soprotivljaemosti razrusheniju trubnih stalej po rabote razvitija treschinji / V. E. Remorov, N. A. Cheljishov, Ju. I. Pashkov, A. B. Kaplan // Izvestija vjisshih uchebnjih zavedenij. Chernaja metallurhija. - 1991. - \# 8. - S. 31-34. 4. Panasjuk V. V. Metodji otsenki treshchinostojkosti konstruktsionnjih materialov / V. V. Panasjuk, A. E. Andrejkiv, S. E. Kovchik. - K. : Nauk. dumka, 2001. 277 s. 5. Shanjavskij A. A. Samoorhanizatsija kinetiki ustalostnjih treshchin / A. A. Shanjavskij // Sinerhetika i ustalostnoje razrushenije materialov. - M. : Nauka, 1989. -246 s. 6. Bernal I. D. Geometrical approach to the structure of liquids / J. Appl. Phys. Lett. - 2000. - Vol. 44. - \# 9. - P. 874-876. 7. Shanjavskij A. A. Sinerheticheskij podhod $k$ postroeniju edinoj diahrammi rosta ustalostnjih treshchin v materialah / A. A. Shanjavskij, E. M. Hrihoriev // Sinerhetika i ustalostnoje razrushenije materialov. - M. : Nauka, 1989. - 246 s. 